\title{
Los géneros periodísticos informativos en la actualidad internacional
}

\author{
Dra. Pastora Moreno Espinosa \\ Profesora Titular de Redacción Periodística \\ Universidad de Sevilla
}

\section{RESUMEN}

En la presente investigación haremos un estudio somero de los géneros periodísticos informativos para, con posterioridad, analizar la presencia de dichos géneros en las secciones o los temas internacionales de los periódicos: El País, ABC, El Mundo y La Vanguardia.

\section{ABSTRACT}

This article is a shallow study of the journalistic goods and analyses the presence of this goods in the sections or the international topics of the newspapers: El País, ABC, El Mundo, La Vanguardia.

Palabras claves: Prensa/Redacción periodística/Líneas editoriales.

Key Words: Press/Writting/Editorial Lines.

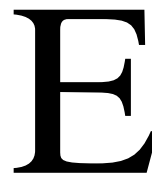

1 periodismo, como método de interpretación de la realidad social, si sirve de géneros periodísticos que cumplen diferentes funciones para responder a las necesidades sociales. Dentro de las necesidades informa tivas de los receptores de un medio, la función de la noticia puede distinguirse perfectamente de la del reportaje, la crónica o de la de todos los géneros de opinión.

En la presente investigación haremos un estudio somero de los géneros periodísticos informativos para, con posterioridad, analizar la presencia de dichos géneros en las secciones o los temas internacionales de los periódicos: El País, ABC, El Mundo y La Vanguardia.

Según Martínez Albertos, «podrían definirse los géneros periodísticos como las diferentes modalidades de la creación literaria destinadas a ser divulgadas a 
través de cualquier medio de difusión colectiva» $1 . \mathrm{Y}$ se refiere al periodista como un operador semántico, o dicho de otro modo: la interpretación periodística de la realidad se expresa a través de una gama de modos y convenciones, que son los géneros periodísticos. Los códigos de la comunicación periodística, añade, se plasman así en unos estilos y géneros propios de un lenguaje que se diferencia claramente de otros tipos de lenguajes (el literario, el administrativo, etc.).

Además de esto, los géneros periodísticos son géneros que reflejan el acontecer de un suceso y su interpretación, es decir, la información correspondiente y su comentario o valoración por parte del periodista. Para Javier del Rey «los géneros periodísticos serían como una red que el colectivo profesional de los periodistas lanza sobre eso que llamamos «el mundo», para racionalizarlo y explicarlo, y la teoría y sus categorías -la de que existen los géneros periodísticos, y la de que son éstos, y no cualesquiera otros-, expresarían ese esfuerzo para conseguir que la malla sea cada vez más fina» 2 .

La distinción entre los diferentes tipos de géneros es una convención social. Javier del Rey afirma que la realidad no nos ofrece un editorial, una noticia, una crónica o un reportaje. La realidad es más modesta y se limita a estar ahí. Lo demás -la noticia, el reportaje, el editorial y la crónica- lo pone el medio para recoger la complejidad de lo que acontece y exponerlo a los receptores. Los géneros periodísticos producen orden y concierto en el material informativo, y avalan la legalidad de la comunicación ${ }^{3}$.

Los géneros periodísticos son el resultado de una lenta evolución histórica ligada a la evolución del mismo concepto de lo que se entiende por periodismo. A lo largo de la historia del periodismo cada uno de los géneros no ha tenido la importancia que en la actualidad nosotros le damos. La aparición histórica de los géneros periodísticos está estrechamente relacionada con las distintas etapas del periodismo en cuanto hecho cultural. Según el profesor Angel Benito «en líneas generales puede afirmarse que el periodismo posterior a 1850 supone una serie de conquistas de primera magnitud: la conquista de todas las capas de la sociedad, de casi todos los países de la tierra y de todos los temas (...). El periodismo de este siglo largo -1850-1973- puede dividirse en tres etapas bien definidas. Periodismo ideológico, periodismo informativo y periodismo de explicación. Esta clasificación, que responde a los últimos estudios de prensa comparada realizados en el

1 MARTINEZ ALBERTOS, J.L.: «Periodismo. Géneros», en obra colectiva Gran Enciclopedia Rialp , Madrid, 1974, Tomo XVIII. Vid también Curso General... Op. Cit., p. 272.

2 DEL REY, J.: Estatuto epistemológico de la redacción periodística, en Revista de Ciencias de la información, vol. 5, Facultad de Ciencias de la Información, Universidad Complutense, Madrid, 1988, p. 102.

3 DEL REY, J.: Estatuto epistemológico ....Op. Cit., p. 116. 
mundo, se funda en la consideración de los fines que en cada uno de estos tres períodos se han propuesto los profesionales de la información» 4 .

Por tanto, Angel Benito distingue en el periodismo a partir de 1850 tres etapas bien definidas:

A. El periodismo ideológico llega hasta el fin de la primera guerra mundial. Se caracteriza por ser un periodismo al servicio de ideas políticas y religiosas. Es un tipo de prensa con muy pocas informaciones y muchos comentarios, realizada sobre todo por literatos. En ella impera la opinión sobre la información y tienen importancia el artículo, el comentario y el ensayo.

$\mathrm{B}$. El periodismo informativo aparece hacia 1870 y coexiste durante cierto tiempo con el periodismo ideológico. Se centra más en la narración o relato de los hechos que en las ideas, como la etapa anterior. Tienen más importancia los géneros informativos: la noticia, la crónica y el reportaje.

C. El periodismo de explicación aparece después de la segunda guerra mundial. Supone un reciclaje de las dos etapas anteriores, motivado, sobre todo, por la aparición de la radio y la televisión y las consecuencias sociales que de ello se derivan. El periodismo de explicación aborda los hechos en profundidad y utiliza equilibradamente los géneros básicos, (relato y comentario), situándolos en una nueva perspectiva mediante la cual el lector encuentra los juicios de valor al lado de la narración de los hechos de forma inmediata. Pretende, por tanto, informar y crear opinión a la vez.

Por consiguiente, de acuerdo con su forma discursiva, los géneros periodísticos pueden clasificarse en dos grupos:

1. Los que dan a conocer hechos, que utilizan la forma expositiva, descriptiva y narrativa.

2. Los que dan a conocer ideas, que usan fundamentalmente la forma argumentativa.

Esteban Morán Torres ${ }^{5}$ sostiene en su libro Géneros del periodismo de opinión que el género interpretativo tiene como elemento principal las ideas. En el periodismo de opinión el objetivo prioritario se centra en la implantación y mantenimiento de unos determinados principios.

La información en prensa escrita ha quedado en las últimas décadas desbordada por la instantaneidad que ofrecen los medios que aportan rapidez de transmisión. Si el éxito de la comunicación se basara exclusivamente en la rapidez de la transmisión de noticias, la prensa escrita sería ya del pasado. Pero los periódicos ofrecen una serie de ventajas de importancia sobre los medios audiovisuales, como

4 BENITO, A.: Teoría General de la Información: I. Introducción, Madrid, 1973, p.71.

5 MORAN TORRES, E.: Géneros del periodismo de opinión. Eunsa, Pamplona, 198. p.10. 
la interpretación de los hechos y la explicación de las causas, antecedentes y consecuencias que puedan derivarse.

Morán Torres, asimismo, piensa que en el periodismo podemos encontrar dos vertientes principales: la interpretación (opinión) y la información. Y aunque es necesario realizar un gran esfuerzo para conseguir la máxima simplificación a la hora de clasificar los géneros periodísticos, este autor distingue cuatro géneros informativos y cuatro de opinión:

- Informativos: noticia, entrevista, crónica y reportaje.

- De opinión: artículo editorial, comentario, columna y crítica periodística.

$\mathrm{Y}$ reconoce que se trata de un ordenamiento discutible, pero que elimina una serie de ambigüedades y complicaciones que caracterizaban a los cuadros de géneros periodísticos que se han aplicado en determinadas obras de consulta.

Por su parte, Juan Gutiérrez Palacio mantiene en su obra El comentario periodístico: los géneros persuasivos ${ }^{6}$ que los géneros periodísticos son modos convencionales de captar y traducir la realidad. Las reglas por las que se rigen son bastante flexibles y admiten muchas variedades. Para él, lo fundamental es que cada uno cumple una función distinta y cubre un sector del amplio arco que va desde la noticia hasta el editorial. Destaca cuatro géneros periodísticos: información, reportaje, crónica y artículo o comentario, cada uno con su propia técnica de trabajo.

Por tanto, el número de géneros en cuestión, depende de los diferentes autores. Por nuestra parte, nosotros distinguimos: la noticia, la entrevista, la crónica y el reportaje, entre los géneros informativos y el editorial, el artículo, la columna y la crítica, entre los de opinión. Reseñaremos, a continuación, exclusivamente los géneros periodísticos informativos para aplicarlos a la actualidad internacional.

\section{GENEROS INFORMATIVOS. ASPECTOS TEORICOS.}

1. La noticia.

Es noticia todo aquello que ocurrió o que va a ocurrir y que, a juicio del periodista, tendrá gran repercusión social.

Según Mar Fontcuberta ${ }^{7}$ etimológicamente noticia procede de la palabra nova que significa cosas nuevas. Su propósito consiste en informar de un acontecimiento noticioso oportunamente, aunque Carl Warren ${ }^{8}$ considera que noticia puede ser aquello que le interesa publicar al director de una redacción.

6 GUTIERREZ PALACIO, J.: Periodismo de opinión. Paraninfo, Madrid, 1984. p. 99.

7 FONTCUBERTA, M.: Estructura de la noticia periodística. ATE, Barcelona, 1980. p. 9.

8 WARREN,C.: Géneros periodísticos informativos. ATE, Barcelona, 1979. p. 31. 
Uno de los autores más clásicos del periodismo, Emil Dovifat, afirma que la noticia constituye una «comunicación sobre los hechos surgidos en la lucha por la existencia del individuo y de la sociedad» y considera que deberá ser:

«1. De utilidad y valor para el receptor.

2. Nueva, es decir, recién transmitida.

3. Ser comunicada a través de un tercero y, por consiguiente, expuesta a la influencia subjetiva de éste. Esta influencia, que abarca desde el error inconsciente hasta la orientación consciente de la misma, está destinada a provocar en el receptor una determinada decisión» ${ }^{9}$.

Por su parte Martínez Albertos define la noticia como «un hecho verdadero, inédito o actual, de interés general, que se comunica a un público que pueda considerarse masivo, una vez que haya sido recogido, interpretado y valorado por los sujetos promotores que controlan el medio utilizado para la difusión ${ }^{10 "}$.

Para investigar una noticia el periodista tiene en cuenta varias preguntas: ¿Qué?, ¿Quién?, ¿Cómo?, ¿Cuándo?, ¿Dónde?, ¿Por qué? y al responder a ellas se obtiene información completa. La respuesta al qué se refiere al suceso, al acontecimiento que se considera de interés como para comunicarlo. El quién completa la información aclarando la persona que es el sujeto de la acción. También las demás preguntas precisan detalles en relación con el suceso y completan la noticia.

La estructura de la noticia depende, en general, del espacio y del tiempo disponible al que deberá ajustarse el periodista. Así en relación al espacio y el tiempo la forma más común de la información es de pirámide invertida.

En la entrada, las primeras líneas, se escriben los detalles más importantes de la información de manera que con sólo leer esta parte, el lector se entera genéricamente de lo que sucede. Posteriormente se desarrolla el suceso, para dar paso a todos los datos secundarios que en un momento dado pueden llegar a suprimirse sin que pierda sentido el contenido de la noticia.

\section{La entrevista.}

La entrevista es el género mediante el cual un profesional de la información, el periodista, entra en contacto con un personaje público, el entrevistado, del que se presupone interés periodístico, bien por sus declaraciones, por su cargo o por su propia personalidad.

Por consiguiente, la entrevista tiene como propósito dar a conocer mediante la reproducción de la imagen, una situación, un hecho, etc.

9 DOVIFAT, E.: Periodismo.., Op. Cit., p. 51-52.

10 MARTINEZ ALBERTOS, J.L.: Redacción Periodística: Los estilos y los géneros en la Prensa diaria, Barcelona, ATE, 1974. p. 37. 
No obstante, hay que tener en cuenta que existe una pluralidad de intereses reales que se parapetan tras el acto concreto de conversar, sin que ello implique minimizar el interés de todo texto periodístico: conectar con el público lector. Y es que la entrevista es algo más que una simple conversación que agota todos sus objetivos en el propio placer de la interlocución y posee una finalidad concreta que trasciende la efímera satisfacción del momento conversacional.

Ahora bien, nunca se debe tomar esta diferenciación en sentido estricto, porque siempre es posible encontrar excepciones que vienen a confirmar esa regla. Entre esas excepciones se encuentran los entrevistadores que, desenfadadamente, aprovechan una conversación casual con un personaje popular para esbozar su entrevista periodística.

Desde otro ángulo, hay que entender la entrevista como un sistema de comunicación en el que el entrevistador haría las veces de emisor, el público-lector se constituiría en el receptor, y el medio que acogiera la publicación haría las funciones de canal. En este sistema, la entrevista periodística no sería otra cosa distinta a un metalenguaje que diese cuenta del auténtico mensaje de ese sistema.

Por tanto, por entrevista no hay que entender sólo el momento conversacional entre dos interlocutores, previamente puestos en contacto, sino el texto final que el periodista redactará con posterioridad a ese encuentro, porque, aunque su finalidad primaria es describir, también se apoya en el relato para dar mayor interés al mensaje o puede ceñirse al esquema de preguntas y respuestas. A veces una forma puede servir de eje central y la otra a modo de refuerzo; la elección depende en este caso del periodista, más que del propio género. Así, la entrevista puede escribirse siguiendo un orden cronológico y respetando la estructura básica de preguntas y respuestas y también se puede redactar en forma de relato, en cuyo caso no se sigue el orden de preguntas y respuestas tal como fueron hechas, y tampoco se incluyen en el texto.

Por su parte, Montserrat Quesada distingue entre entrevista informativa y entrevista de creación. Según ella, «la entrevista informativa es la que centra toda su atención y remite todo su interés a las declaraciones de determinados personajes públicos, pues son éstas las que aportan el indispensable ítem de actualidad y justifican la oportunidad de su publicación» ${ }^{11}$. Por el contrario, la entrevista de creación es aquella otra en la que «intervienen muy esencialmente las dotes personales de quien la realice: observación, ambiente, creación y recreación, mundo de resonancias y de sugestiones, más prosa propia que ajena, dirección, en fin, de orquesta» ${ }^{2}$.

11 QUESADA, M.: La entrevista : obra creativa. Mitre, Barcelona, 1984. p. 11.

12 ACOSTA MONTORO, J.: Periodismo y Literatura, Ediciones Guadarrama. Colección Universitaria de Bolsillo. Punto Omega. Madrid, 1973. Tomo II. p. 327. 
Según Siegfried Mandel, en lo que concierne a su estructura puede ser variable, pero la forma más frecuente es aquella que se inicia con «una cita indirecta, una aseveración interpretativa, un resumen o, a veces, una cita directa. Al principio de la nota, por lo común en el primer párrafo o en el segundo, se identifica al entrevistado, se demuestra su capacidad o autoridad en el tema de la entrevista y se aclara la ocasión e importancia de la misma. El cuerpo de la entrevista es una combinación de citas directas e indirectas, diseminadas con frases o párrafos explicativos de transición» ${ }^{13}$.

Otra técnica para la redacción de entrevistas es transcribir las preguntas y respuestas en el orden que se llevaron a cabo, o bien escoger la opinión que se considere más importante, empezar con ella y luego seguir el orden de preguntas y respuestas. En cualquier caso, la estructura de la entrevista consta de tres partes fundamentales:

1. La presentación o entrada.

2. El desarrollo, con las preguntas y respuestas o el relato.

3. El cierre, que puede ser un comentario, la última respuesta o el final del relato.

\section{La crónica.}

El género de la crónica procede de la literatura más clásica, la de los escritores griegos y romanos que con este vocablo designaban las narraciones de aquellos hechos bélicos que eran contados por sus propios protagonistas o testigos siguiendo un orden temporal. Y es que el tiempo es la primera dimensión que encierra el concepto de crónica, cuya expresión formal procede del término griego cronos, que significa tiempo.

Hasta el nacimiento del Periodismo tal y como hoy lo entendemos crónica era propiedad exclusiva del mundo de la literatura y de la historia. En ellos se manifestaba como un relato rico en recursos expresivos y valoraciones personales cuyo resultado último se hallaba en muchos casos más cercano al mundo de la ficción que al de la realidad.

La entrada de la crónica en el quehacer periodístico es un hecho que sólo tiene lugar en los países latinos. Los periodistas que adoptan el modelo de la crónica se ven obligados a realizar sobre ella una serie de modificaciones, a fin de reconducir el género hacia el terreno de la información de actualidad sin renunciar a su carácter personal e interpretativo. Por este motivo la mayoría de los autores que han estudiado el género de la crónica coinciden en otorgarle un cúmulo de características que intentan conciliar las propiedades ambiguas de un género híbrido por naturaleza. De entre estos rasgos destacamos tres: limitación del 
suceso en el tiempo y en el espacio, la necesidad de testimoniar el relato con la presencia in situ del informador y la inclusión de juicios valorativos procedentes del cronista en la propia narración de los acontecimientos.

Llegados a este punto nos hacemos eco de la definición que nos da Mariano Cebrián Herreros quien considera que la crónica es «la información sobre unos hechos ocurridos durante un período de tiempo desde el lugar mismo o próximo a donde han ocurrido por un informador que los ha vivido como protagonista testigo o investigador y que conoce las circunstancias que lo rodean» ${ }^{14}$.

Lo que parece ser el principal motivo de controversia en la crónica es su carácter híbrido, esa ambivalencia del género que hace que la información de los hechos reales y noticiables se mezclen continuamente con la interpretación y el comentario que de ellos hace el cronista.

Pero la combinación de estos elementos no es aleatoria. Toda valoración que se haga en la crónica debe quedar supeditada a la exposición e información de los hechos. Es esta premisa, que se impone como una norma insalvable en algunos libros de estilo como el del diario El País ${ }^{15}$, la que distingue a la crónica de cualquier otro género periodístico.

No obstante, la visión personal que siempre aporta esa especie de «notario de los hechos» ${ }^{16}$ en que se convierte el cronista es la que permite al medio diferenciar su oferta informativa de la de otros medios que se surten exclusivamente de las noticias de agencia o que están supeditados a las versiones de los hechos que dan las emisoras o periódicos más acreditados.

El valor testimonial que el cronista otorga a la narración, y toda la carga subjetiva que ello trae consigo, es, si el cronista está bien compenetrado con su medio de comunicación, una forma de interpretar la realidad que la emisora, el periódico o la revista en cuestión, pretende difundir. De no ser por la originalidad y la novedad de los datos que aporta el cronista y por la interpretación personal que de los mismos efectúa, las empresas periodísticas se ahorrarían gran parte de su presupuesto utilizando en la elaboración de sus servicios informativos los datos que todos los días aportan las agencias.

La crónica es el principal ingrediente periodístico para hacer que las secciones informativas de los periódicos o emisoras se conviertan en escenarios para la narración original y novedosa.

Pero no es nuestra intención dar a entender que la crónica es un género para el comentario. Lo cierto es que la mayoría de los profesionales que ejercen este tipo de periodismo coinciden en destacar lo poco conveniente que resulta recargar la crónica con juicios de valor.

\footnotetext{
14 CEBRIAN HERREROS, M.: Géneros informativos audiovisuales. Ciencia 3, Madrid, 1992. p. 88.

15 EL PAIS, Libro de estilo. Ediciones El País, Madrid, 1990. p.109.

16 CEBRIAN HERREROS, M.: Géneros informativos ....Op. Cit., p. 92.
} 
Otra de las características de la crónica es su regularidad que da lugar a que un mismo autor, un mismo tema o un mismo espacio de referencia se repitan con frecuencia. Esta repetición termina creando en el lector de la crónica un vínculo de familiaridad que sólo es comparable en periodismo al que se establece entre los columnistas y su público. El beneficio es mutuo: el destinatario se conforma al oír esa visión de los hechos que en tantas ocasiones le ha agradado; el cronista se permite la libertad de escribir en un estilo llano, directo, desenfadado, como si se tratase de una correspondencia epistolar entre viejos amigos. El autor de crónicas se convierte así en algo mucho más importante para el lector que un reportero ocasional, se transforma en un confidente.

Como todo género periodístico, la crónica se presta a la clasificación en grupos, a la división en categorías, hasta configurar un amplio abanico de variantes en las que el aspirante a cronista puede realizarse.Y en este sentido, todos los estudiosos de la crónica aluden, directa o indirectamente, a la diferenciación postulada por Lorenzo Gomis ${ }^{17}$ entre crónicas que cubren un lugar y crónicas que cubren un tema. Dentro de las crónicas que se hacen para informar de todo cuanto suceda en un lugar concreto están las crónicas de corresponsal y las crónicas de enviados especiales. Al segundo tipo, es decir, a aquellas que se elaboran atendiendo a la especialización que el cronista manifiesta en un determinado tema, corresponden las crónicas judiciales, las deportivas, las de sucesos, las taurinas, las de sociedad, las crónicas parlamentarias...

La crónica posee un valor testimonial, ofrece la visión de unos hechos que el informador ha presenciado, una visión avalada por la autoridad del periodista, según la especialización temática del acontecimiento, el dominio que se tenga de la técnica de confección y el conocimiento que éste evidencie sobre el lugar donde se ha producido. Es inevitable, además contextualizar y documentar todas las informaciones. Según Cebrián Herreros, el cronista es «un historiador del lugar, un notario de 1 os hechos especialmente cualificado, un profesional que recodifica una realidad de la que ha sido testigo con la intención de transmitirla a un público disperso y heterogéneo. La redacción final responde a impresiones aprehendidas por el cronista y a las consideraciones generales diseñadas por el medio, sean formales, técnicas o estilísticas.

De otra parte, la extensión de la crónica no es fija. Suele tener variaciones asombrosas y su límite puede determinarse, en última instancia, por el espacio que se le otorgue en el periódico.

La estructura de la crónica es la siguiente:

1. La presentación o entrada. 
2. El relato, que incluye detalles que permiten al lector «vivir» el suceso.

3. La conclusión, que no es un juicio conclusivo puesto que no hay razonamiento, sino que se trata del final del relato.

\section{El reportaje.}

El reportaje es un género que puede incluir otros géneros en su estructura narrativa, especialmente la entrevista. Es un género narrativo en el que se combina la narración con la descripción.

El término reportaje procede del francés «reportage», pero por los estudios efectuados parece probable que el tronco común a todos los idiomas se encuentre en el término latino «reportare» con el significado de contar, anunciar, traer o llevar una noticia. Por tanto, hace referencia al aspecto esencial de todo reportaje que es la narración.

Sobre este género afirma Mariano Rojas Avendaño que es el género que permite una mayor capacidad expresiva individual y la experimentación de nuevas formas y que partiendo de la exigencia de la objetividad y de la fidelidad a la realidad, admite plena libertad de tratamiento. Según él «el reportaje brilla sobremanera cuando la sociedad pasa por momentos de tensión: guerras, huelgas, cataclismos, epidemias, o trata de reflejar la vida diaria de un grupo o de una persona» 18 .

En opinión de Mariano Cebrián el reportaje es una escapada de la información rutinaria de las redacciones para buscar los aspectos recónditos de las noticias. «Es la mirada de un reportero que actúa con libertad de concepción y con tiempo suficiente; incluso en los casos en que esté bastante apremiado nunca tiene que trabajar con la celeridad del informador de un telediario» 19 .

Y sobre todo, el reportaje lo que intenta no es descubrir noticias, sino profundizar en ellas. Como ha destacado George Hills «no se pretende dar a conocer noticias, sino informar a hacer recordar al público los antecedentes de una noticia o los distintos aspectos de un problema que se considere de interés público y de actualidad ${ }^{20 "}$.

El reportaje es una profundización que supone un análisis y una interpretación en la presentación y desarrollo de la información, aunque luego en la redacción dicha interpretación queda más diluida. De todos modos, es una interpretación que no puede confundirse con una valoración y menos aún con una opinión ${ }^{21}$.

18 ROJAS AVENDAÑO, M.: El reportaje moderno. Universidad Autónoma, México, 1976, p. 156.

19 CEBRIAN HERREROS, M.: Géneros informativos ...Op. Cit., p. 149.

20 HILLS, G.: Los informativos en radiotelevisión. ORTV, Madrid, 1987.

21 MAcDOUGALL, C.: Reportaje interpretativo. Diana, México, 1983. 
Hay que tener en cuenta que el reportaje se refiere a hechos e ideas y que es informativo, no literario.

El reportaje parte de la actualidad, pero se recrea en ella, no necesita su inmediatez como la noticia. Puede dedicarse perfectamente al trasfondo que existe en la inmediatez de la información y a buscar lo permanente y lo humano. Por tanto, lo más frecuente es que el reportaje se centre en temas de actualidad más duradera, sin estar supeditado al tiempo, como la noticia o la crónica.

Genéricamente, es el género que permite intensificar mejor los recursos expresivos que cada medio puede ofrecer. Al ser en sus formas expositivas el género más libre, favorece el uso de nuevas técnicas narrativas.

En el reportaje se comunica algo que despierta en el lector la necesidad de actuar, por lo que en ocasiones no se trata sólo de información, sino también de denuncia. Así, se hace la presentación detallada del hecho para que el lector lo viva y de este modo se forme un criterio y actúe conforme a él. Como género informativo exige una profunda investigación documental, observación de campo y entrevistas, pero su propósito es además interpretativo. Supone, por tanto, una interpretación del suceso, que refleja la propia experiencia del periodista y que hace que sea el género periodístico más extenso.

El reportaje se estructura en una presentación o entrada que debe incluir lo más importante para captar la atención del lector. Después, los enunciados se redactan de manera que en ningún momento decaiga el interés. En esta parte del reportaje se pueden intercalar diálogos textuales que incluyan modismos del lenguaje o detalles anecdóticos que hagan más reales a los personajes del relato. Desde luego, la redacción del final es igualmente importante porque con él precisamente se satisface al lector. Es conveniente, entonces, cerrar mediante una frase contundente que recoja la idea inicial o ponga de relieve el tema central del reportaje. Se compone de tres partes igualmente importantes:

1. Una presentación con garra.

2. Un desarrollo: el relato (información e interpretación).

3. Una conclusión, es decir, el fin del relato .

El lenguaje del reportaje se caracteriza por el uso de enunciados y párrafos simples. Por otro lado, la narración se mezcla con el lenguaje informativo y expresivo (emotivo).

ORIGENES Y EVOLUCION DE LOS DIARIOS ESTUDIADOS: $A B C, E l$ País, El Mundo y La Vanguardia.

\section{EL PAÍS}

Bajo la dirección de Juan Luis Cebrián, El País salió a la calle por primera vez el 4 de mayo de 1976, aunque llevaba cuatro años tratando de obtener la 
oportuna autorización administrativa, que no llegó hasta esa fecha. En la actualidad, forma parte del grupo mediático Prisa (Promotora de Informaciones S.A.) ${ }^{22}$ que dirige Jesús Polanco y compite en el liderazgo de la prensa española con el diario deportivo Marca, aunque en Andalucía tiene una difusión menor que el diario $A B C$, más implantado.

El editorial de El País es un texto de obligada lectura diaria en los ámbitos político y económico de España, donde está considerado como un texto de enorme influencia. Ocupa un espacio fijo, abriendo la sección de "Opinión". El número de editoriales varía entre uno y tres, según la importancia de las noticias comentadas.

La columna está siempre presente en la última página, de la mano de Rosa Montero, Manuel Vicent, Joaquín Vidal y Maruja Torres, entre otros. Estas columnas, como señalan Armañanzas y Días Noci, son del tipo literario, haciendo referencia a temas sociales, humanos o culturales ${ }^{23}$.

$A B C$

$A B C$ nace y se desarrolla con la familia Luca de Tena, responsable también de la empresa editora, Prensa Española S.A., que tomó la dirección del periódico en algunas etapas. Esta familia poseía hasta 1977 el 94,5\% de las acciones. Este dominio accionarial se ha diversificado un poco en los últimos años, cambiando, por consiguiente, la composición del Consejo de Administración, aunque bajo la presidencia de Guillermo Luca de Tena y Brunet.

$A B C$ sale por primera vez a las calles de Madrid en 1903, como periódico semanal. El 1 de junio de 1905, ABC se convirtió en diario, y en 1929 comenzó la edición de Sevilla. Numerosos han sido los problemas que ha tenido que salvar $A B C$ en sus cerca de cien años de historia, problemas que, en alguna ocasión, afectaron a su línea editorial. Durante la Guerra Civil, Prensa Española S.A., que también editaba Blanco y Negro, quedó bajo el Gobierno republicano hasta que las tropas franquistas entraron en Madrid, en marzo de 1939. El fin de la contienda trajo para Prensa Española S.A., entre otras cosas, la imposibilidad de publicar Blanco y Negro. Esta situación se mantuvo hasta 1957, año en el que la Dirección General de Prensa otorgó la autorización solicitada insistentemente desde 193924.

Como recuerdan Armañanzas y Días Noci, durante la dictadura franquista " $A B C$ se vio afectado por la supresión de la libertad de expresión, al igual que el resto de publicaciones del país, y sufrió continuas multas y censuras, sobre todo entre 1953 y 1958. Con la Ley de Prensa de 1966 sufrió el primer secuestro desde

22 Prisa está presente en la práctica totalidad de ámbitos mediáticos de nuestro país. Cuenta , entre otros medios, con El País, As, la Cadena Ser, Canal +, Canal Satélite Digital y se está implantando en el campo de la prensa local, haciéndose con periódicos de tirada provincial o autonómica en la comunidad autónoma andaluza, El Correo de Andalucía, entre otros. Además, tiene una importante red editorial a la que hay que sumar las cadenas de distribución.

23 Ib. p. 203.

24 ALFÉREZ, A.: El cuarto poder en España, Plaza y Janés, Madrid 1987. 
la Guerra Civil por la publicación de un artículo de Luis María Ansón titulado "La Monarquía de todos", en el que apostaba por una Monarquía constitucional y democrática.

Si ABC había mostrado cierto talante liberal en la época franquista, cuando esta etapa estaba muriendo no supo reaccionar a tiempo y quedó como un diario con un lastre empresarial del que le costó comenzar a salir ${ }^{25}$.

La dirección de Prensa Española S.A. trató de encauzar el rumbo económico y periodístico de $A B C$ con el nombramiento de Ansón como director en enero de $1983^{26}$. Desde la dirección de $A B C$, recuperó la tirada y cambió el estilo del periódico con unas portadas muy forzadas hacia temas polémicos e introducciones breves de textos de opinión en todas las secciones ${ }^{27}$.

En 1985, Prensa Española S.A. enderezaba el rumbo obteniendo beneficios -unos cien millones de pesetas- por primera vez desde 1975, al tiempo que cambiaba la composición de su accionariado, dando entrada en el Consejo a personas ajenas a la familia fundadora. Además, afrontó el coste del traslado a talleres nuevos, la mejora de la distribución, aumento y redefinición de la publicidad, adquisición de un equipo tecnológico más acorde a las nuevas exigencias del sector, así como el reajuste de la plantilla. Francisco Jiménez Alemán, director de la cabecera sevillana, sucedió a Ansón al frente de ABC, y afrontó la difícil remodelación del diseño y estructuras del diario. Su paso por la dirección fue breve, siendo sustituido por José Antonio Zarzalejos, su actual director.

\section{EL MUNDO}

El Mundo del Siglo XXI nace el 23 de octubre de 1989, seis días antes de las elecciones generales y se nutre, desde un principio, de periodistas salientes de Diario 16, periódico de complicada viabilidad debido a las enormes deudas económicas.

Este periódico da mucha importancia a los géneros de opinión. De hecho, a diferencia de El País, entre otros, es la primera sección del diario, con cinco páginas en las que da cabida a una variada modalidad de textos de opinión. El editorial varía entre uno o dos, y los domingos se une el artículo del director, Pedro J. Ramírez, bajo el título genérico "Carta del domingo", en el que se exponen las líneas maestras de la política editorial de El Mundo. Diariamente, la sección de "Opinión" se abre con la columna "Zoom", en la que escriben colaboradores habituales entre los que se encuentran Manuel Hidalgo o Gabriel Albiac.

25 Ib. p. 176.

26 El partido Socialista Obrero Español, con Felipe González al frente, había ganado las elecciones generales en octubre de 1982, con un respaldo masivo que le otorgó mayoría absoluta para gobernar.

27 ARMAÑANZAS, E. y DIAZ NOCI, J.: Periodismo y argumentación. Géneros de opinión. Universidad del País Vasco, Bilbao, 1996. p. 177. 
Las viñetas, tras el abandono de Forges -que recalaría en El País ${ }^{28}$ - son responsabilidad de Gallego\&Rey, abriendo el apartado denominado "Impresiones" en la página 2, y Ricardo y Nacho, en la siguiente. Varios son los sueltos: "Vox Populi", en el que se hace una valoración diaria de personajes de actualidad; el que firma "Erasmo" o "La Tronera" de Antonio Gala, además de otros sin rúbrica, que tienen el carácter de un editorial muy breve. Al igual que la mayoría de diarios, tiene un espacio denominado "Tribuna libre", en el que se invita a diferentes firmas.

\section{LA VANGUARDIA}

La Vanguardia es un periódico de gran tradición en Cataluña que ocupa siempre un puesto destacado en el ranking de ventas de prensa diaria en España (OJD). Propiedad de Javier Godó, conde de Godó, es el medio de bandera del grupo mediático del mismo nombre. Fue fundado en 1881 por Carlos y Bartolomé Godó, y su actual director es José Antich.

Según Armañanzas, La Vanguardia se ha situado tradicionalmente entre $A B C$ y El País en cuanto al espacio dedicado a la opinión 29. El comentario, repartido por todas las secciones del periódico, es el género de opinión más común, seguido del artículo. Los editoriales oscilan entre uno y tres.

Junto a los editoriales se ubica la Revista de Prensa, con extractos de los diarios de mayor importancia en el mundo. Además del apartado de Cartas al director, La Vanguardia ofrece un espacio generoso a las columnas y artículos.

\section{PRINCIPIOS IDEOLOGICOS.}

\section{EL PAÍS}

Este diario está considerado entre sus lectores y los especialistas como un diario de calidad. Esta mención encuentra su refrendo documental en 1980, cuando apareció clasificado como tal en el libro de John C. Merrill y Harold A. Fisher (1980). Años más tarde, Gérard Imbert, José Vidal Beneyto y, de nuevo, John C. Merrill clasificarían El País como un diario de referencia, denominación de la que hacen gala sus directivos cada vez que tienen que participan en conferencias y mesas redondas sobre el tema. Según Imbert y Vidal Beneyto, El País ha llegado a convertirse en «un representante formal de una opinión pública que, por otra parte, ha contribuido él mismo a formar» ${ }^{30}$.

28 Al respecto, véase la columna que el dibujante firmó en la página 31 de El País el 14-2-1995, titulada "Me voy de El Mundo, para recuperar mi propio equilibrio". Forges fue uno de los miembros del equipo fundador de El Mundo, procedente de Diario 16 al igual que la mayoría de la Redacción del diario que dirige Pedro J. Ramírez.

29 ARMAÑANZAS, Emy, El color del dinero. El boom de las subastas de arte, acontecimiento cultural en prensa, Rekargi, Bilbao 1993.

30 IMBERT, Gerard y VIDAL BENEYTO, José (coords.), El País o la referencia dominante, Mitre, Madrid 1986. 
El ideario del periódico está fuertemente condicionado por los planteamientos defendidos la época en la que nació, y se recoge en el Libro de Estilo: «El País se define estatutariamente como un periódico independiente, nacional, de información general, con una clara vocación de europeo, defensor de la democracia pluralista según los principios liberales y sociales, y que se compromete a guardar el orden democrático y legal establecido por la Constitución». Según Armañanzas y Díaz Noci, la imagen de independencia de la que hace gala el diario en su Libro de Estilo «se ha ido velando aunque no se le deje de reconocer la importancia que ha tenido en la historia reciente de la prensa de este país (...) Al diario El País se le ha ido enturbiando el país real; la larga lista de denuncias de corrupción lanzadas contra el Gobierno socialista le ha aguado la fiesta; el apoyo que ha dado a ese partido, ahora difícil de defender» ${ }^{31}$.

\section{$A B C$}

El editorial del 1 de junio de 1905 afirmaba que "en política, $(A B C)$ no seguirá bandera alguna para no mermar su independencia, dentro de la cual se propone vivir sin abdicar uno solo de sus fueros". La empresa editorial, Prensa Española S.A., toma el propio editorial como lugar donde dejar clara su línea ideológica: "es este primer número de $A B C$ el testimonio de sus propósitos: es su credo, su programa, su plan de trabajo".

En opinión de Jean Michel Desvois, en la primera mitad del siglo " $A B C$ era el diario de la oligarquía, es decir, de la aristocracia, de la gran burguesía, de la Iglesia y, seguramente, de buena parte de la pequeña burguesía reaccionaria de provincias que se sentía solidaria de la clase dominante" ${ }^{2}$. Como detallan Emy Armañanzas y Javier Díaz Noci en un interesante y completo estudio, "la defensa que $A B C$ ha hecho siempre de la Monarquía le trajo problemas en distintas etapas históricas. Durante la República, el Gobierno se incautó de Prensa Española S.A.; más tarde reaparece $A B C$, y en ocasiones sucesivas sufre la suspensión porque, aunque era considerado como el gran periódico de oposición, era vigilado de cerca" 33 .

Sus páginas han alternado en distintas etapas las firmas de los colaboradores habituales de ideología liberal-conservadora (José María de Areilza, José María Pemán) con intelectuales marginados por el régimen franquista (José Luis López Aranguren, José Luis Sampedro, Ramón Pérez de Ayala, etc., algunos de ellos acabaron dejando sus páginas), con colaboradores de la derecha más recalcitrante" ${ }^{34}$.

31 ARMAÑANZAS, E. y DÍAZ NOCI, J., op. cit. pp. 182-183.

32 DESVOIS, Jean Michel, La crisis del Estado Español, Editorial Cuadernos para el Diálogo, Madrid 1978. p. 317.

33 ARMAÑANZAS, E. y DIAZ NOCI, J., op. cit. p. 139.

34 ARMAÑANZAS, E. y DIAZ NOCI, J., op. cit. pp. 135-176. 
Su línea ideológica se complementa con la defensa de la unidad de España y postulados abiertamente anticomunista, en lo político, y partidario, desde su fundación, de la libertad de mercado, desde el punto de vista económico. En lo social, ha defendido los valores religiosos, en concreto los de la Iglesia Católica, y se ha mostrado contrario a cualquier cambio legislativo que quisiera modificar los preceptos católicos, como la Ley del Aborto y sus posteriores modificaciones, aunque se define como laico y no confesional.

Con Ansón al frente del diario, el periódico se sitúa en la oposición política para ejercer como tal, manteniendo una actitud muy crítica con el Gobierno de Felipe González. En su labor de acoso y derribo al Ejecutivo socialista, la dirección de $A B C$ diseñó un proyecto empresarial en el que el diario El País pasaba a ser el contrincante con quien se jugaba el liderazgo en ventas, ignorando prácticamente al resto de la prensa.

$\mathrm{Al}$ contrario de lo que sucede en el caso de El País ${ }^{35}$, el Libro de estilo de $A B C$ no incluye sus principios editoriales ni cuenta con una especificación amplia de los propósitos de Prensa Española S.A. Para encontrar una referencia precisa, tenemos que remitirnos a la carta que Guillermo Luca de Tena, accionista y editor, escribió a los lectores con motivo del 75 aniversario de $A B C$ (1980), en la que afirmaba que España siempre había sido "la máxima preocupación del diario, compatible con su liberalismo, tomado no como un credo sino como una actitud constante de tolerancia". Recordaba los problemas que la postura ideológica asumida había ocasionado a $A B C$ en las diferentes etapas históricas. En la misma línea, afirmaba que "si en anteriores etapas de su vida $A B C$ sirvió de reducto al sentimiento nacional, si en otras fechas su declarado monarquismo sirvió para mantener en alto muchas ilusiones, hoy consagramos todo nuestro esfuerzo a una ardiente y sincera voluntad de concordia" 36 .

\section{EL MUNDO}

La portada del primer número de $E l$ Mundo, a seis días de unas elecciones generales, daba pistas inequívocas de por dónde iría la línea editorial de un diario que tenía a Pedro J. Ramírez como director, después de una salida de Diario 16 forzada por las continuas informaciones que ponían en evidencia la acción del Gobierno de Felipe González. El titular a tres columnas de esa primera portada fue

35 El Libro de Estilo de El País (Edics. El País, 1993) comienza con un capítulo titulado "Principios", en el que desgrana los postulados de su política editorial y orientaciones acerca de la responsabilidad profesional, el tratamiento de la información y la publicidad, el uso de las fotografías y las normas a tener en cuenta a la hora de realizar entrevistas o hacerse eco de encuestas, así como la normativa del diario cuando deban reproducirse determinadas expresiones.

36 LUCA DE TENA, Guillermo, "Razones para una fidelidad" en $A B C, 28-6-1980$. 
el siguiente: "El PSOE perderá la mayoría absoluta si hay una fuerte participación electoral" ${ }^{37}$.

Este diario ha dedicado buena parte de sus esfuerzos a lo que se ha dado en llamar "periodismo de investigación", con el que, según reconocen Armañanzas y Díaz Noci, "ha levantado ampollas, tanto en círculos políticos como entre algunos sectores periodísticos" ${ }^{38}$. Entre estos últimos cabe destacar la notoria confrontación con la línea informativa de El País, diario al que continuamente se consideraba alineado con el poder socialista desde las páginas de El Mundo. Por el contrario, los adversarios políticos y periodísticos del diario que dirige Pedro J. Ramírez le han achacado continuamente cierto sensacionalismo, y subrayan el riesgo de "realizar un juego peligroso para la democracia" como consecuencia de las continuas acusaciones al poder de actuaciones ilegales.

Los principios ideológicos de El Mundo vienen recogidos en su Estatuto de Redacción. Este ideario ve la luz pública a través del editorial del 15 de diciembre de 1990: "El Mundo aspira a ser un periódico progresista, comprometido con la defensa del actual sistema democrático, las libertades públicas y los derechos humanos".

La incidencia de El Mundo en el devenir político de España ha sido decisiva en los últimos años. No son pocos los analistas que asocian la llegada de José $\mathrm{M}^{\mathrm{a}}$ Aznar al Gobierno con la línea informativa de El Mundo, en Prensa, la Cope en Radio y Antena 3 en Televisión.

\section{LA VANGUARDIA}

Ideológicamente, este diario se ha ubicado tradicionalmente en la misma línea conservadora que $A B C$, siendo la referencia informativa de la emprendedora burguesía catalana.

Recientemente, los entresijos económico-mediáticos han puesto en más de un aprieto al Grupo Godó, cuya participación en la compra de Antena 3 Radio por el Grupo Prisa resulta, para muchos, cuando menos sospechosa. Además, la pasividad demostrada en el tratamiento informativo de algunos de los escándalos informativos durante los últimos años de Gobierno socialista situó a este diario en la misma estrategia que El País, lo cual fue ampliamente criticado desde los medios que más se implicaron en el sucesivo descubrimiento de escándalos políticos.

37 El Mundo, 23-10-1989, p. 1

38 ARMAÑANZAS, E. y DÍAZ NOCI, J. , op. cit., p. 184. 


\section{LOS GENEROS PERIODISTICOS INFORMATIVOS EN LA SECCION INTERNACIONAL DEL PERIODICO.}

\section{EL PAIS}

El diario El País presenta la información internacional en sus primeras páginas, desde la número dos hasta la diez, aproximadamente.

Se trata de alrededor de diez o quince informaciones por día, redactadas en su mayoría como noticias y reportajes. En algunos casos específicos se encuentran crónicas como «Bush mantiene una corta ventaja antes de la certificación de los resultados en Florida» ${ }^{39}$.

En general, se tocan todos los continentes. Hay informaciones bastante extensas de las elecciones en Estados Unidos, el tema de Fujimori (Perú), la crisis de Oriente Próximo, Haití, y Europa con temas del Parlamento Europeo, por ejemplo.

Los temas se presentan como noticias extensas y los reportajes y las entrevistas no aparecen con mucha frecuencia. Los primeros sí las incluyen habitualmente y resaltan las declaraciones textuales de los políticos y de los testigos de los hechos relatados ${ }^{40}$.

La información internacional de El País suele centrarse en temas de violencia, guerra, muerte, ausencia de libertades y derechos humanos ${ }^{41}$ y en menor medida en tratados internacionales y visitas de jefes de estado extranjeros. las regiones más mencionadas son las de Oriente Medio, Africa, Europa y Estados Unidos por problemas o acuerdos políticos, económicos, etc.

La diagramación en general guarda el mismo aspecto que en el resto del periódico, en el que el tamaño de los titulares se relaciona con el grado de importancia de la noticia en cuestión. Los titulares suelen contener términos negativos como pesadilla, procesamiento, guerra, etc ${ }^{42}$.

Emplea fotografías en cada página, por lo menos una, que suele ser de políticos o de acontecimientos extranjeros. Muestran imágenes de violencia o rostros inquietantes de las personas que sufren los hechos narrados. En ocasiones, los epígrafes de las fotografías describen momentos que luego serán detallados en el texto de la noticia o reportaje.

También es común la inclusión de mapas o infografías de las regiones afectadas para ubicar al lector ante la noticia ${ }^{43}$.

39 «Bush mantiene una corta ventaja antes de la certificación de los resultados en Florida», en El País, lunes, 27 de noviembre de 2000.

40 «El nuevo Gobierno peruano releva a doce altos jefes militares afines a Montesinos», en El País, lunes, 27 de noviembre de 2000 .

41 «Hezbolá reabre el frente de guerra contra Israel al atacar una patrulla al sur de Líbano», en El País, lunes, 27 de noviembre de 2000 .

42 Ibidem pp. 2 a 13.

43 Ibidem p. 13. 
En cuanto al contenido de la información podría decirse que El País utiliza un lenguaje claro, que pretende en primer lugar informar al lector y suministrarle aspectos generales y específicos de los temas tratados. Se manifiesta con numerosos sustantivos y adjetivos negativos, dando un panorama bastante pesimista en cuanto a los problemas de países en guerra o con problemas de violencia. Sin embargo, es más optimista en tema europeos.

\section{$A B C$}

El periódico $A B C$ sitúa la información internacional, con este mismo nombre, en la página 30 aproximadamente, después de la nacional, bajo título de NACIONAL y antes de ANDALUCIA. Ofrece a diario alrededor de diez o quince informaciones redactadas en su mayoría como noticias.

Cuenta con corresponsales o enviados especiales para las noticias más destacadas, como por ejemplo, «los palestinos aparcan la intifada y desenfundan la guerra de guerrillas» 44 y el resto son redactadas en base a los cables de las agencias de noticias. Esto puede explicar que no se encuentren entrevistas, ni grandes reportajes en la información internacional.

La información se divide en distintas zonas geográficas: Europa occidental, Europa del Este, Iberoamérica, Extremo Oriente, etc.

La diagramación sigue el estilo del resto del periódico con un titular general que da pie a otros menos relevantes dentro de una misma noticia y utiliza fotos y gráficos en las informaciones más destacadas ${ }^{45}$.

El contenido de la información es diverso y trata de tener presencia en casi todos los asuntos internacionales importantes y en las regiones en conflicto. Presenta tres o cuatro temas de manera destacada, como el conflicto árabe-israelí, la carrera hacia la casa blanca, el ex-dictador Pinochet, etc., a través de corresponsales y enviados especiales, y el resto de la información la presenta de forma más sintética y aséptica.

\section{EL MUNDO}

El periódico El Mundo presenta la información internacional de las páginas 15 a 25, aproximadamente, bajo el titular «EUROPA» y «MUNDO». Están precedidas por las noticias nacionales y las de sociedad.

Es posible encontrar los cuatro géneros periodísticos informativos, aunque la información se presenta mayoritariamente con noticias y reportajes.

\footnotetext{
44 «Los palestinos aparcan la intifada y desenfundan la guerra de guerrillas», en $A B C$, jueves, 2 de noviembre de 2000 .

45 «Jerusalén recupera sus peores pesadillas», en $A B C$, viernes, 3 de noviembre de 2000.
} 
Una de las crónicas es la que detalla algunos hechos relacionados con la muerte de un niño iraquí en Alemania ${ }^{46}$ o sobre las elecciones norteamericanas ${ }^{47}$, que se acompaña de un cronograma de los hechos destacados.

En ocasiones, los reportajes, además de incluir entrevistas y alguna fotografía, presentan un anexo de información con alguna noticia de menor relieve o un comentario anecdótico ${ }^{48}$.

En cuanto a los temas, existe una clara preferencia por los temas europeos y los que atañen a Estados Unidos. También a la problemática en Hispanoamérica.

En comparación con El País, este periódico presta más atención a la mediación europea o estadounidense frente a los problemas del Tercer Mundo.

Las fotografías incluyen mayor número de fotos de políticos y menos zonas de enfrentamientos u otro tipo de problemas. Los titulares apuntan a temas de actualidad política 49 .

Su diagramación no difiere de la del resto del periódico, con titulares que se adaptan a la importancia concedida a la información y fotografías en prácticamente, todas las páginas.

El contenido de la información, como ya recogíamos antes, hace hincapié en temas concernientes a la Unión Europea, en su política y economía, y a noticias de países europeos vecinos, como Francia y Alemania. Se puede afirmar que es más de tendencia europeísta.

En definitiva, su modo de informar es analítico con explicaciones de documentos y proyectos de ley de trascedencia internacional, pero, sobre todo, europea.

\section{LA VANGUARDIA}

Este diario presenta la información internacional al principio, a partir de la página 3 y hasta la página 15, más o menos, según la cantidad de noticias del día.

Utiliza mayoritariamente reportajes, para el relato de las noticias más destacadas, en los que se aportan datos nuevos y declaraciones, con la mayor parte de las informaciones cubiertas por corresponsales y enviados especiales ${ }^{50}$.

La Vanguardia también utiliza entrevistas a políticos como medio de información de un hecho especialmente trascendente ${ }^{51}$.

46 «Los testigos confirman la tesis racista en la muerte del niño iraquí», en El Mundo, lunes, 27 de noviembre de 2000.

47 «Bush se perfila como el vencedor en florida con tan sólo 454 votos más que su rival Gore», en El Mundo, lunes, 27 de noviembre de 2000.

48 «El suspense del culebrón electoral continúa», en El Mundo, lunes, 27 de noviembre de 2000.

49 «La vuelta de Milosevic provoca indignación en Belgrado y La Haya» o «El kursk, probable víctima de uno de sus propios torpedos», en El Mundo, lunes, 27 de noviembre de 2000.

50 «Héroes por accidente»o «Jospin reafirma su línea política y rechaza un giro a la izquierda del PS francés» en La Vanguardia, lunes, 27 de noviembre de 2000.

51 Entrevista a Romano Prodi, Presidente de la Comisión Europea: «Si Francia no retira el derecho a veto, la cumbre de Niza puede ser un fracaso» en La Vanguardia, lunes, 27 de noviembre de 2000. 
Algunas informaciones son ampliadas con gráficos explicativos que favorecen que éstas puedan ser leídas y entendidas fácilmente. Por lo general, este planteamiento de la información se presenta en los casos de noticias de suma actualidad, como las elecciones en Estados Unidos ${ }^{52}$.

La diagramación es clara, y se utilizan muchos recuadros para enmarcar la información y destacarla. Son interesantes los encabezamientos ya que presentan una síntesis clara y completa de la noticia que se va a desarrollar. Algunas informaciones tienen un seguimiento diario y se ubican bajo un titular genérico que las identifica. Es el caso de la campaña electoral de Estados Unidos ${ }^{53}$. También se valen de fotografías pero sin presentar los aspectos más desgarradores de los hechos, y de gráficos y mapas para aclarar situaciones en particular.

En cuanto a sus contenidos, La Vanguardia centra su información internacional en los acontecimientos más destacados como la batalla judicial entre Bush y Gore, el conflicto de Fujimori en Perú, el conflicto árabe-israelí, etc.

La Vanguardia presenta un estilo neutro en sus informaciones, con expresiones que presentan acciones concretas, sin adjetivaciones innecesarias. Esto determina un tono alejado de dramatizaciones. También se profundizan y se constatan las informaciones con corresponsales y enviados especiales, que manteniendo ese tono más bien desdramatizado, aportan datos que enriquecen el relato.

\section{EN CONCLUSION...}

Recapitulamos, a continuación, algunos aspectos generales de las secciones internacionales de El País, ABC, El Mundo y La Vanguardia:

Estos diarios utilizan habitualmente los géneros periodísticos informativos: La noticia, la entrevista, el reportaje y la crónica; sin embargo, los más utilizados son la noticia y el reportaje. El género menos utilizado parece ser la entrevista y se encuentran muy pocas durante el período analizado. Esto tal vez se deba a lo poco accesibles que son algunas personalidades importantes del panorama internacional, lo cual se contrapone a la facilidad que supone transcribir sus declaraciones conseguidas en conferencias de prensa y transmitidas por las agencias de noticias.

Sin embargo, la entrevista es un género excelente para conocer aspectos importantes de personalidades de diversos lugares de mundo que de otra manera no se conocen y sirven para, en algunos casos, acercarse a las motivaciones de estos personajes que, con sus actos, pueden influir en la vida cotidiana de los lectores.

En la sección internacional cobra un papel destacado el género del reportaje, ya que profundiza la relación de los hechos y explica al lector diversos aspectos

52 «LLorida otorga la victoria a Bush», en La Vanguardia, lunes, 27 de noviembre de 2000.

53 «La carrera hacia la casa Blanca», en La Vanguardia, lunes, 27 de noviembre de 2000. 
de otros países y culturas que de otra manera dificultarían su entendimiento. Se aportan gráficos de fechas importantes que permiten establecer una breve historia de los acontecimientos y por tanto recordar sus causas originales. Y esto es importante, porque en repetidas ocasiones la información internacional se presenta explicando los últimos hechos y dando por sentado que el lector conoce y ha leído en los últimos días el origen y desarrollo de la situación.

Los diarios de mayor tirada, El País y El Mundo, se sirven de corresponsales en diversos puntos del mundo para cubrir la información y obtener datos más cercanos de los hechos. Es notoria la diferencia cuando sólo se redacta a partir de agencias.

La diagramación de la sección internacional de cada periódico sigue las mismas líneas que el resto de las informaciones. Por lo general, se utilizan muchas fotografías que acercan los hechos al lector y que, en algunos casos cumplen las funciones apelativas marcadas.

En general, los periódicos en su sección internacional centran su mensaje en la información de los hechos, sin mostrar soluciones a problemas ni sugerencias. Sólo en algunos casos se realiza una llamada de atención sobre le peligro de algunos temas o se formulan deseos de solución de las situaciones planteadas. También según la tendencia política de los periódicos, se centran más en Europa, o no. Los temas elegidos y a los que ya se ha hecho referencia, corresponden a los establecidos por casi todos los medios de comunicación, tanto escritos como audiovisuales, según las informaciones de esos momentos. El resto de temas internacionales de menor importancia son relatados en las noticias breves o directamente no se mencionan. En la sección de breves, la agenda de temas no es tan rigurosa y en ocasiones se incluyen noticias extranjeras, según su grado de rareza. Es de destacar que siempre el marco de cobertura internacional se centra preferentemente en occidente. Países orientales o más alejados como Australia, India, Corea, Alaska, etc. quedan fuera de la cobertura noticiosa, a excepción de que ocurra algún acontecimiento fuera de lo común. 